\title{
Amélia Janny 1842-1914: estudo, antologia e bibliografia, por Maria Aparecida Ribeiro.
}

\author{
Lisboa: Biblioteca Nacional de Portugal; Centro \\ de Literaturas e Culturas Lusófonas e Europeias \\ (CLEPUL); Centro Interdisciplinar de Ciências \\ Sociais (CICS.NOVA), 2019.
}

Susana Vieira

Centro de Literaturas e Culturas

Lusófonas e Europeias

\section{DoI}

https://doi.org/10.37508/rcl.2021.n46a46o

Vinda a lume em 2019, numa edição muito bem organizada e anotada por Maria Aparecida Ribeiro, Amélia Janny 1842-1914 é um volume inserido no projeto desenvolvido pela Linha de Investigação "Brasil: literatura, memória e diálogos em Portugal" do Centro de Literaturas e Culturas Lusófonas e Europeias da Faculdade de Letras da Universidade de Lisboa e editado em parceria com o Centro Interdisciplinar de Ciências Sociais da Faculdade de Ciências Sociais e Humanas da Universidade Nova de Lisboa e a Biblioteca Nacional de Portugal, para o estudo e a divulgação da produção de autoria feminina do Almanaque de lembranças $\mid$ Almanaque de lembranças luso-brasileiro | Novo almanaque de lembranças luso-brasileiro, de que 
já constam edições de outras escritoras, nomeadamente de Anália Vieira do Nascimento, Maria José da Silva Canuto ou Alba Valdez. Em palavras das organizadoras do projeto (o supramencionado estudo e divulgação da produção de autoria feminina do Almanaque, de que a obra ora resenhada faz parte), Isabel Cruz Lousada e Vania Pinheiro Chaves,

urge, já avançado o século XXI, dar "palco" - posto que voz tiveram, na história coeva - às figuras femininas que teimam em não deixar passar do umbral do esquecimento, séculos volvidos de uma existência digna e meritória de destaque (RIBEIRO, 2019, p. 10).

No presente volume, pretende-se recuperar uma das escritoras mais proeminentes de uma Coimbra novecentista, marcada pelo labor e os cantos poéticos do romantismo. A edição, além de incluir um estudo detalhado sobre a vida e obra de Janny, abre o devido espaço à sua antologia e anexa, numa extensa bibliografia ativa (cerca de vinte e uma páginas), os títulos publicados em edições periódicas várias, além de participações em outras obras e informação de "Recortes de periódicos sem indicação de fonte ou com fonte incompleta” (RIBEIRO, 2019, p. 466). Todo este trabalho foi empreendido por Ribeiro, que também dedicou um pequeno anexo a complementos gráficos, nomeadamente um retrato da escritora e gravuras com poemas seus, de que se destaca a transcrição de uma das estrofes do canto III de Os lusíadas feita por Janny.

Escritos com ortografia atualizada, segundo o novo acordo ortográfico da língua portuguesa de 1990, os textos de Amélia Janny

1 Janny foi convidada, em 1883, a participar na Grande edição manuscrita dos lusíadas pelos contemporâneos ilustres de Portugal e Brasil, dirigida por Teófilo Braga, uma edição que se propunha apresentar transcrições feitas pela pena de "ilustres" da época sobre o manuscrito Os lusíadas, numa linguagem modernizada e acessível. 
publicados no Almanaque de Lembranças são apresentados em ordem cronológica da data de publicação (...) Seguem-se uma tradução feita pela autora, paródias a poesias de Amélia Janny, textos de sua autoria traduzidos por outrem, e, por último, poemas e prosas que lhe são dedicados (RIBEIRO, 2019, p. 13).

revelando o carinho e interesse literário que contemporâneos seus lhe devotavam. A sua produção disseminada por "Outros periódicos, coletâneas e dispersos” (RIBEIRO, 2019, p. 141-394) é superior em número de poemas em relação à que se encontra coletada sob o título "Almanaque de lembranças" (RIBEIRO, 2019, p. 87-137) e que ironicamente abre com um "Adeus", no qual a autora vem "grata relembrar as rosas, / Que me ofertara festival prazer, / Neste recinto de amizade e encanto, / Que talvez nunca tornarei a ver!” (RIBEIRO, 2019, p. 87).

No estudo exaustivo, relatório de todas as referências que envolveram e enformaram a vida da escritora, dá-se conta das suas raízes coimbrãs, mas também da vivência de - e em - uma Coimbra de estudantes e lentes universitários, "paisagem humana” completada por figuras castiças e conhecidas entre os locais, cruzando-se em festas populares, tabernas, manjares e gastronomias tertulianas, discussões e diversões... Como moldura, o tópico descreve-nos o património natural e dos monumentos edificados ao longo da história “dessa Coimbra de festas e brutalidade”, a par da qual igualmente se ambientava "uma Coimbra literária que poetava a sério, discutia literatura, ia a teatros, criava jornais e neles colaborava. São de recordar a Questão Coimbrã, e os inúmeros periódicos, quase todos de vida efémera, entre os quais $A$ folha, criado por João Penha” (RIBEIRO, 2019, p. 26-27). Nessa Coimbra

não havia mulheres cujo nome merecesse figurar nas memórias dos estudantes. De facto, são poucas as referidas nos textos por nós compulsados e todas elas mulheres do povo (...) No entanto, a partir da segunda metade do século XIX, havia mulheres que iam ao teatro, como se pode ver pelos jornais da época. Entre essas, 
Amélia Janny, colaboradora assídua de vários periódicos, presença sempre festejada, que, ao longo da vida, foi ganhando vários epítetos - Nova Safo, Poetisa do Mondego, Cisne do Mondego... Alguém que se tornou um símbolo da cidade, um mito, e que surge, em prosa ou verso, em notícias, homenagens e recordações. (RIBEIRO, 2019, p. 27).

Iniciando-se com publicações no Lis, Janny seria aplaudida entusiasticamente, e em diversas ocasiões, por Castilho, num sarau literário orientado pelo próprio, ao lado de outros nomes consagrados, como Quental, Braga e Junqueiro, onde declamaria poesia da sua autoria. "Fosse pelo conteúdo dos versos, fosse pela voz e pela figura jovem e frágil, fosse por ser mulher - e uma mulher de Coimbra e em Coimbra - a verdade é que a fama de Amélia Janny espalhou-se e se foi consolidando" (RIBEIRO, 2019, p. 33). Foi homenageada em versos de Henriqueta Elisa, João de Deus, António Fogaça, Teixeira de Pascoaes, Luís Carlos, Maria Amália Vaz de Carvalho, Eugénio Ribeiro, Francisco de Carvalho, Santos Valente, Cândido de Figueiredo, Alfredo de Campos, Matilde Areosa, Maria Amália Braz, Júlia de Gusmão, João de Vilhena; correspondeu-se com Eugénio de Castro, Bastos Pina ou António Cândido da Costa; publicou em periódicos portugueses, brasileiros e franceses; era convidada para as festas proeminentes de Coimbra, nas quais intervinha com poemas seus. Mas porque na Fonte dos Amores nem todas as lágrimas que correm são de amor, o estudo também refere as críticas de que a escritora foi alvo, especialmente por parte de D. Tomás de Noronha que a satirizou em versos parodiantes, de que se reproduz “A Lua e o Sol”, uma peça em três atos a propósito de uma récita de despedida de um grupo de Teologia e Direito; apesar disso, “o prestígio de Amélia Janny, aos sessenta anos, continuou e transcendeu as fronteiras de Portugal. Em 1901, foi mencionada como "Poetisa do Mondego", ao lado de Clorinda de Macedo, a "Musa do Porto", no livro de Concepción Gimeno de Flaquer: La Mujer Intelectual" (RIBEIRO, 2019, p. 51). 
Após a sua morte, a Gazeta de Coimbra iniciou uma campanha para a reunião da sua obra, que se seguiu até 1932. O longo tempo despendido deveu-se a razões de vária ordem, especialmente resultantes das dificuldades naturais de composições não datadas, não anotadas, de recortes sem se conhecer a existência das publicações, de exemplares publicados mas não encontrados. Para a grande empreitada revelou-se de inegável importância a contribuição de amigos (e descendentes) e admiradores, e ainda o trabalho de Zolino da Silva Figueiredo que, entre jornais, recuperou noventa e quatro poemas de Janny, apesar de se tratar de uma pesquisa quase rudimentar nos preceitos essenciais, em especial por não mencionar a fonte ou transcrever os versos com sílabas por ela rejeitadas, ela que era uma “metrificadora exemplar!" (RIBEIRO, 2019, p. 65).

Os seus versos, na maioria, de circunstância - por ocasião de falecimento ou celebração de aniversário de familiares e amigos, de revelações artísticas, inaugurações, apresentações de visitantes ilustres, festas de caridade -, de inspiração romântica, pautam-se pela formosura da palavra e da construção e por temas relacionados com a natureza (uma natureza parnasiana), a noite, a ruína, o enaltecimento dos que se lhe devotavam, ou com a sua Coimbra: “Amélia Janny, que sempre fez questão de cultivar os signos e tradições de Coimbra, foi, aos poucos, passando ela própria a ser marca da cidade" (RIBEIRO, 2019, p. 61). Era na sua "Coimbra, linda cidade, / (na que) Nada te vence em primores: / Tens num Penedo, a saudade, / Tens numa Fonte, os Amores. / Tens serenatas dolentes / Onde palpita a paixão", que sentia o conforto para compor e se expor, cidade cantada em muitos dos seus verbos e sentida em tantos outros. Porém, a contrariar esta natureza de enraizado e fixo símbolo da cidade onde nascera, se formara, morrera e que, no fundo, alimentara essa mesma relação sígnica, a poeta escreveria em 1883 o curioso - e relevante - pequeno texto "No álbum dum artista", no qual se lê que "O artista [sendo a poeta o artista, o per- 
former da palavra sublime, que compõe e recita] não tem pátria. / É seu destino correr / atrás dum vulto fantástico / que lhe sorriu ao nascer." (RIBEIRO, 2019, p. 118).

A propósito, Ribeiro lembra a investigação de Ana Lopes que, centrando-se em Janny, supõe que, "movimentando-se em campos intelectuais e sociais selecionados, onde era conhecida e afamada, não quis correr os riscos" (RIBEIRO, 2019, p. 69). No mote da problemática está o facto de a poeta revelar alguma indisponibilidade para colaborar com A voz feminina: "embora conheça que o lugar que elas (as suas poesias] vão ocupar poderia ser empregado mais agradavelmente" (RIBEIRO, 2019, p. 69). Janny atravessou uma época como uma pequena onda que se percebe atravessada por um mar imenso, um mar de discussões e iniciativas em torno dos direitos e da visibilidade das mulheres escritoras, em busca de um quarto seu, e de tendências várias, confluências de correntes e experiências literárias fixadas em edições mais ousadas, em registos mais expressivos. Aparentemente, e apesar desse confronto, ter-se-á mantido imutável... como um signo. Ainda assim escreveu, em muitas das suas composições poéticas, linhas que a faziam considerar esse imponente - e quase indomesticado - cavalo, que era o progresso, cingindo-o, contudo, a "esta terra, que eu amo, / Esta Coimbra formosa, / De seus filhos orgulhosa, / Ter um risonho porvir! / E há-de esta voz, exprimindo / Quanto hoje minha alma sente, / Bradar-vos, ansiosa e crente: / Não descansar - progredir!” (RIBEIRO, 2019, p. 221). No mesmo texto não atravessa imaculadamente o vocábulo, porquanto se dá o seu passo como “Palavra mágica, / Sedutora, eterna fada!”, “Mistério esplêndido, / Às gerações revelado” (RIBEIRO, 2019, p. 207), é também “Pomposo túmulo / Dos negros erros d'outrora!" (RIBEIRO, 2019, p. 207)... e o texto progride na mesma ideia, quase ironia.

Os ideais da estética do romantismo continuariam a manifestar-se declaradamente em muitas das suas criações, assim nos evidencia a leitura de textos como “O ermo”, título já de si denunciador do que 


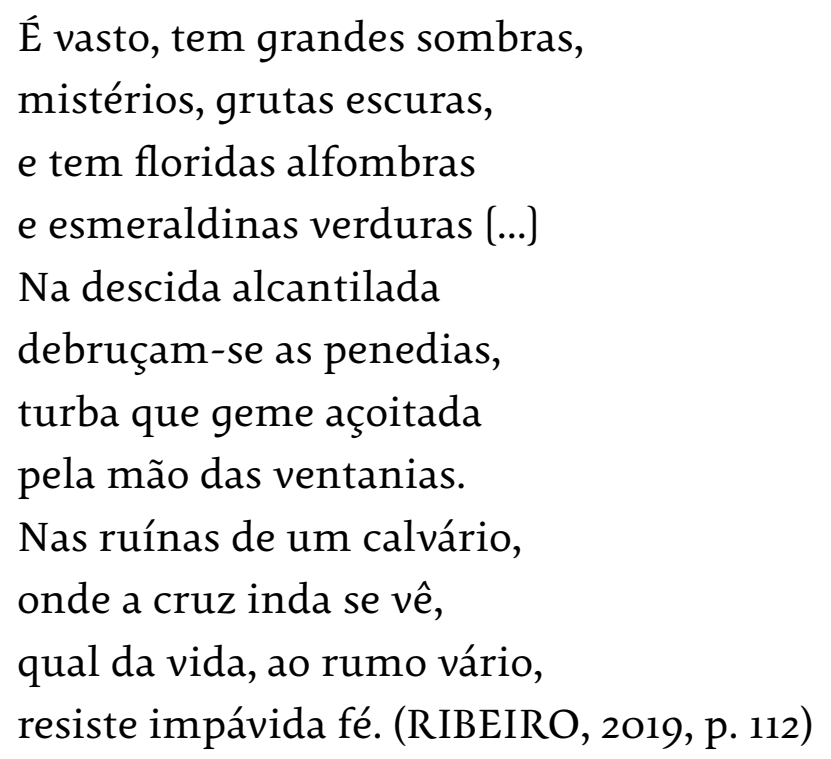

E ainda o tema da noite, cantado onde versifica o que a envolve, como aquele em que se confessa amar "a noite quando o vento ruge, / E a tempestade seus bramidos solta; / Qual a procela rebentando n'alma, / Que se resolve na desgraça envolta." (RIBEIRO, 2019, p. 16o). Ou quando, evocando, epigraficamente, o Eurico de Herculano, se inspira na edificação do "Impossível”, esse "pomo vedado / Do éden da minha vida (...) / Murmurando sem cessar / Que me ilude e me convida / Sem nunca a poder tocar!” (RIBEIRO, 2019, p. 214), ao passo que, ante esse mesmo "impossível” é ela "o verme imperceptível, / Que esmagas, sem ver o que é! / Tu és pra mim o impossível / Onde expira a minha fé!” (RIBEIRO, 2019, p. 215). Já a inspiração parnasiana pode observar-se em textos como este:

Há um mês também a lua,
Despontando no horizonte,
Mostrava a límpida fronte
Em todo o fulgor seu;
Também sorria orgulhosa
Ao mirar-se docemente
Sobre o espelho da corrente,
Mas não era neste céu!... 


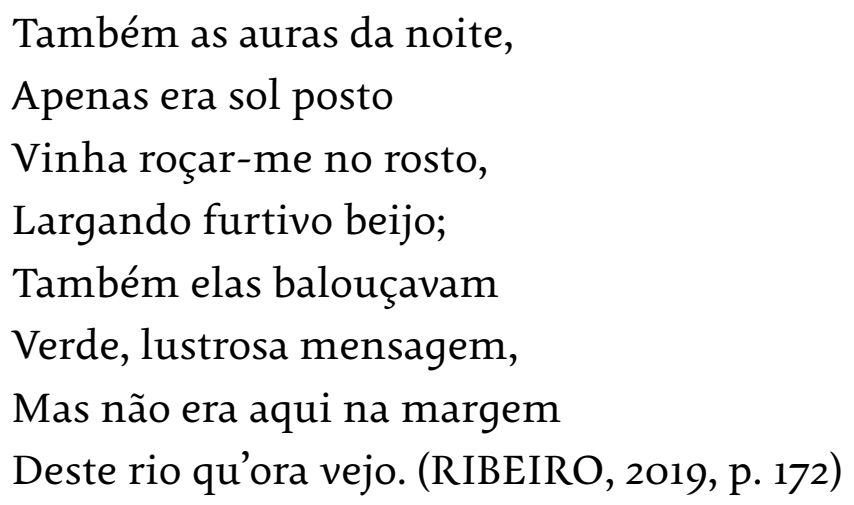

E é "na margem / Deste rio", o Mondego, que enquadramos e lemos os seus poemas como um cisne belo que passa e nos deixa a sua leveza e o seu sonho, na manifestação da sua fidelidade a uma cidade e a uma luz, a da Poesia, superior à condição de quem a escreve. Aspetos estes que, tal como já indicado, podemos observar no estudo, antologia e bibliografia elaborados por Maria Aparecida Ribeiro na obra Amélia Janny.

RECEBIDO: $13 / 07 / 2021$ APROVADO: $12 / 08 / 2021$

\section{REFERÊNCIAS}

RIBEIRO, Maria Aparecida. Amélia Janny 1842-1914: estudo, antologia e bibliografia. Lisboa: Biblioteca Nacional de Portugal; Centro de Literaturas e Culturas Lusófonas e Europeias (CLEPUL); Centro Interdisciplinar de Ciências Sociais (CICS.NOVA), 2019.

\section{MiNicuRRículo}

Susana vieira é Doutoranda em Estudos da Literatura (Instituto de Estudos de Literatura e Tradição da Universidade Nova de Lisboa) e investigadora integrada na linha "Brasil: literatura, memória e diálogos em Portugal" (Centro de Literaturas e Culturas Lusófonas e Europeias da Universidade de Lisboa), tem participado em congressos internacionais e publicado artigos e ensaios relacionados com a literatura portuguesa e brasileira; é docente no Instituto de Cultura e Língua Portuguesa (Universidade de Lisboa). 